\title{
PROFIL PENDERITA MORBUS HANSEN (MH) DI POLIKLINIK KULIT DAN KELAMIN BLU RSUP PROF. DR. R. D. KANDOU MANADO PERIODE JANUARI - DESEMBER 2012
}

\author{
${ }^{1}$ Patricia I. Tiwow \\ ${ }^{2}$ Renate T. Kandou \\ ${ }^{2}$ Herry E. J. Pandaleke \\ ${ }^{1}$ Kandidat Skripsi Fakultas Kedokteran Universitas Sam Ratulangi Manado \\ ${ }^{2}$ Bagian/SMF Kulit dan Kelamin RSUP Prof. Dr. R. D. Kandou Manado \\ Email: patriciatiwow@yahoo.com
}

\begin{abstract}
Hansen's Disease is a chronic infection disease caused by Mycobacterium leprae. The transmission of this disease is by direct contact with Hansen's Disease patients in a long period of time, and by inhalation. This study aimed to evaluate the profile of hansen's disease patients in Dermatovenereology clinic of Prof. Dr. R. D. Kandou Hospital Manado during the period from January - December 2012. This is a descriptive retrospective study. The result of this study showed that among 112 patients with hansen's disease, the highest rate was within 25-44 age group (46.4\%), where male patients outnumbered females (64.3\%). Most of the patients reside in the district of Singkil (12.5\%). Multibacillary leprosy was most frequent (89.3\%). There were $16 \%$ patients with ENL reactions. The disability stage 2 were found in 8,1\% patients. Most patients had no history of treatment with MDT (54.5\%).
\end{abstract}

Keywords: Hansen's Disease, profile.

\begin{abstract}
Abstrak: Morbus Hansen (MH) adalah penyakit infeksi kronik yang disebabkan oleh Mycobacterium leprae. Penularan terjadi melalui kontak langsung dalam jangka waktu yang lama dan melalui inhalasi. Penelitian ini bertujuan untuk mengetahui profil penderita morbus hansen di poliklinik kulit dan kelamin BLU RSUP Prof. Dr. R.D. Kandou Manado periode JanuariDesember 2012. Penelitian bersifat deskriptif retrospektif. Hasil penelitian memperlihatkan dari 112 penderita $\mathrm{MH}(10,22 \%)$ terbanyak berasal dari kelompok umur 25-44 tahun (46,4\%), jenis kelamin laki-laki (64,3\%), tempat tinggal kecamatan Singkil (12,5\%), tipe MH terbanyak tipe Multibasiler (89,3\%), terdapat reaksi ENL sebanyak 16\%, kecacatan tingkat 2 sebanyak 8,1\%, dan riwayat pengobatan terbanyak belum pernah melakukan pengobatan MDT sebelumnya (54,5\%).
\end{abstract}

Kata Kunci: Morbus Hansen, profil. 
Morbus Hansen (MH) atau yang dikenal dengan kusta, merupakan penyakit infeksi yang kronik, dimana penyakit ini disebabkan oleh Mycobacterium leprae yang bersifat intraselular obligat. Afinitas pertama dimulai pada saraf perifer, lalu kulit dan mukosa traktus respiratorius bagian atas, kemudian dapat ke organ lain kecuali susunan saraf pusat. ${ }^{1}$ Perkembangbiakan Mycobacterium leprae berlangsung secara perlahan-lahan dengan masa inkubasi \pm 5 tahun. ${ }^{2}$

Klasifikasi $\mathrm{MH}$ menurut WHO (1981), yaitu Pausibasiler (PB) dan Multibasiler (MB). PB adalah kusta dengan basil tahan asam (BTA) negatif pada pemeriksaan kerokan jaringan kulit, sedangkan MB adalah kusta dengan hasil pemeriksaan kerokan jaringan kulit BTA positif. $^{1}$

Di Indonesia, distribusi tidak terjadi secara merata dan distribusi tertinggi terdapat di Pulau Jawa, Sulawesi, Maluku dan Papua. ${ }^{1}$ Penderita $\mathrm{MH}$ pada anak-anak dibawah umur 14 tahun didapatkan \pm 11,39\%, dan jarang sekali ditemukan pada anak dibawah umur 1 tahun. Frekuensi usia terbanyak, yaitu pada usia 25-35 tahun. ${ }^{1}$

Berdasarkan data Dinas Kesehatan Provinsi Sulawesi Utara, total penderita baru MH tahun 2011 berjumlah 408 penderita $(0,018 \%)$ yang terdiri dari 54 penderita $(13,24 \%)$ tipe Pausibasiler (PB) dan 354 penderita (86,76\%) tipe Multibasiler (MB) dari jumlah penduduk 2.281.031 jiwa. Total penderita baru $\mathrm{MH}$ di tahun 2012 berjumlah 444 penderita $(0,019 \%)$ dari jumlah penduduk 2.324.592 jiwa, dimana tipe PB 39 penderita (8,78\%) dan tipe MB 405 penderita $(91,22 \%){ }^{3}$

Penelitian yang dilakukan di Bagian Kulit dan Kelamin RSUP Prof. DR. R.D. Kandou Manado, tercatat jumlah penderita MH dari tahun 2009 sampai 2011 adalah 279 penderita, yang terdiri dari 91 penderita $(9,09 \%)$ pada tahun 2009, 92 penderita $(8,83 \%)$ pada tahun 2010, dan 96 penderita (9,47\%) pada tahun 2011. Berdasarkan penelitian tersebut, ditemukan penderita $\mathrm{MH}$ tipe MB berjumlah 238 penderita (85,30\%) dan tipe PB berjumlah 41 penderita $(14,70 \%){ }^{4}$

\section{METODE PENELITIAN}

Penelitian ini bersifat deskriptif retrospektif. Data diambil dari rekam medik pasien dan buku register morbus Hansen bagian ilmu penyakit kulit dan kelamin RSUP Prof. Dr. R.D. Kandou Manado.

Populasi penelitian mencakup seluruh data pasien yang berobat di poliklinik kulit dan kelamin BLU RSUP Prof. Dr. R. D Kandou Manado periode Januari Desember 2012. Sampel penelitian yaitu data pasien yang didiagnosis morbus Hansen di poliklinik kulit dan kelamin BLU RSUP Prof. Dr. R. D Kandou Manado periode Januari - Desember 2012.

Variabel penelitian meliputi umur, jenis kelamin, tempat tinggal, tipe morbus Hansen, reaksi morbus Hansen, tingkat kecacatan, dan riwayat pengobatan.

\section{HASIL PENELITIAN}

Berdasarkan penelitian retrospektif yang dilakukan di poliklinik kulit dan kelamin RSUP Prof. Dr. R. D. Kandou, serta Pusat Rekam Medik BLU RSUP Prof. Dr. R. D. Kandou pada pasien yang didiagnosis morbus Hansen periode Januari - Desember 2012 didapatkan berjumlah 112 pasien $\mathrm{MH}$ (10,22\%) dari total 1096 pasien yang datang berobat (Tabel 1). 
Tabel 1. Distribusi penderita MH di Poliklinik Kulit dan Kelamin

\begin{tabular}{cccc} 
Tahun & Jumlah Populasi & Jumlah Penderita & (\%) \\
\hline 2012 & 1096 & 112 & 10,22 \\
\hline
\end{tabular}

Distribusi berdasarkan umur, penderita yang didiagnosis $\mathrm{MH}$ paling banyak ditemukan pada kelompok umur 25 - 44 tahun, yaitu 52 pasien $(46,4 \%)$. Tidak ditemukan penderita MH pada kelompok umur $<4$ tahun (Tabel 2).

Tabel 2. Distribusi berdasarkan umur penderita MH

\begin{tabular}{rcc}
\hline Umur & Jumlah & (\%) \\
\hline$<1$ tahun & 0 & 0 \\
$1-4$ tahun & 0 & 0 \\
$5-14$ tahun & 6 & 5,4 \\
$15-24$ tahun & 21 & 18,8 \\
$25-44$ tahun & 52 & 46,4 \\
$45-64$ tahun & 24 & 21,4 \\
$\geq 65$ tahun & 9 & 8 \\
\hline Total & 112 & 100 \\
\hline
\end{tabular}

Distribusi berdasarkan jenis kelamin, penderita $\mathrm{MH}$ ditemukan yang berjenis kelamin laki-laki lebih banyak daripada perempuan yaitu sebanyak 72 pasien (64,3\%). Sementara yang berjenis kelamin perempuan berjumlah 40 pasien (35,7\%). Perbandingan jenis kelamin laki-laki dan perempuan adalah 1,8:1 (Tabel 3).

Tabel 3. Distribusi berdasarkan jenis kelamin penderita MH

\begin{tabular}{ccc}
\hline Jenis Kelamin & Jumlah & (\%) \\
\hline Laki-laki & 72 & 64,3 \\
Perempuan & 40 & 35,7 \\
\hline Total & 112 & 100 \\
\hline
\end{tabular}

Berdasarkan tempat tinggal, penderita $\mathrm{MH}$ yang datang ke poliklinik kulit dan kelamin RSUP Prof. Dr. R. D. Kandou, yang berasal dari kota Manado dan luar kota Manado memiliki selisih yang sedikit, yaitu berjumlah 57 pasien (50,9\%) dan 55 pasien (49,1\%). Penderita $\mathrm{MH}$ yang berasal dari kota Manado, paling banyak terdapat pada kecamatan Singkil dengan jumlah 14 pasien (12,5\%). Pada penelitian ini, tidak ditemukan penderita $\mathrm{MH}$ yang tinggal di kecamatan Sario (Tabel 4). 
Tabel 4. Distribusi berdasarkan tempat tinggal penderita $\mathrm{MH}$

\begin{tabular}{lcc}
\hline \multicolumn{1}{c}{ Tempat Tinggal } & Jumlah & (\%) \\
\hline a. Kota Manado : & 1 & 0,9 \\
1. Kecamatan Bunaken & 13 & 11,6 \\
2. Kecamatan Malalayang & 3 & 2,7 \\
3. Kecamatan Mapanget & 0 & 0 \\
4. Kecamatan Sario & 14 & 12,5 \\
5. Kecamatan Singkil & 8 & 7,1 \\
6. Kecamatan Tikala & 10 & 8,9 \\
7. Kecamatan Tuminting & 4 & 3,6 \\
8. Kecamatan Wanea & 4 & 3,6 \\
9. Kecamatan Wenang & & 49,1 \\
\hline b. Luar kota Manado & 55 & 100 \\
\hline
\end{tabular}

Berdasarkan tipe $\mathrm{MH}$, tipe Multibasiler lebih banyak ditemukan daripada Pausibasiler. Jumlah penderita $\mathrm{MH}$ yang tergolong tipe Multibasiler sebanyak 100 pasien (89,3\%), sedangkan tipe Pausibasiler berjumlah 12 pasien (10,7\%) (Tabel 5).

Tabel 5. Distribusi berdasarkan tipe MH

\begin{tabular}{ccc}
\hline Tipe MH & Jumlah & $(\%)$ \\
\hline Pausibasiler & 12 & 10,7 \\
Multibasiler & 100 & 89,3 \\
\hline Total & 112 & 100 \\
\hline
\end{tabular}

Berdasarkan reaksi $\mathrm{MH}$, ditemukan sebanyak 18 pasien (16\%) mengalami reaksi ENL dan 4 pasien (3,6\%) mengalami reaksi reversal. Adapun 90 pasien baru (80,4\%) yang datang tidak mengalami reaksi MH (Tabel 6).

Tabel 6. Distribusi berdasarkan reaksi MH

\begin{tabular}{ccc}
\hline Reaksi MH & Jumlah & $(\%)$ \\
\hline Reaksi ENL & 18 & 16 \\
Reaksi Reversal & 4 & 3,6 \\
Tidak ada reaksi & 90 & 80,4 \\
\hline Total & 112 & 100 \\
\hline
\end{tabular}


Distribusi berdasarkan tingkat kecacatan, ditemukan paling banyak tidak diperiksa tingkat kecacatan yaitu berjumlah 38 pasien (33,9\%), sedangkan yang datang dengan tingkat kecacatan 0 sebanyak 18 pasien (16,1\%), 11 pasien (9,8\%) dengan tingkat kecacatan 1, dan 9 pasien $(8,1 \%)$ dengan tingkat kecacatan 2 . Terdapat 36 pasien (32,1\%) yang datanya tidak ditemukan (Tabel 7).

Tabel 7. Distribusi berdasarkan tingkat kecacatan

\begin{tabular}{ccc}
\hline Tingkat Kecacatan & Jumlah & $\mathbf{( \% )}$ \\
\hline Tingkat 0 & 18 & 16,1 \\
Tingkat 1 & 11 & 9,8 \\
Tingkat 2 & 9 & 8,1 \\
Tidak diperiksa & 38 & 33,9 \\
Tidak ada data & 36 & 32,1 \\
\hline Total & 112 & 100 \\
\hline
\end{tabular}

Distribusi berdasarkan riwayat pengobatan, ditemukan sebanyak 15 pasien (13,4\%) pernah melakukan pengobatan MDT sebelumnya. Adapun sebanyak 61 pasien $(54,5 \%)$ belum pernah melakukan pengobatan MDT sebelum datang ke RSUP Prof. Dr. R. D. Kandou Manado. Terdapat 36 pasien (32,1\%) yang tidak ada data (Tabel 8).

Tabel 8. Distribusi berdasarkan riwayat pengobatan

\begin{tabular}{ccc}
\hline Riwayat Pengobatan & Jumlah & (\%) \\
\hline Ya & 15 & 13,4 \\
Tidak & 61 & 54,5 \\
Tidak ada data & 36 & 32,1 \\
\hline Total & 112 & 100 \\
\hline
\end{tabular}

\section{DISKUSI}

Dari penelitian retrospektif yang telah dilakukan di poliklinik kulit dan kelamin RSUP Prof. Dr. R. D. Kandou Manado ditemukan sebanyak 112 pasien (10,22\%) yang didiagnosis MH dari 1096 pasien yang datang berobat di poliklinik kulit dan kelamin RSUP Prof. Dr. R. D. Kandou Manado periode Januari Desember 2012. Jumlah penderita baru ini mengalami sedikit peningkatan dibandingkan dengan penelitian sebelumnya yang dilakukan oleh Rompas di poliklinik kulit dan kelamin RSUP Prof. Dr. R. D. Kandou Manado pada tahun 2009-2011 yaitu penderita MH pada tahun 2009 sebanyak 91 penderita (9,09\%), tahun 2010 sebanyak 92 penderita (8,83\%), tahun 2011 sebanyak 96 penderita $(9,47 \%){ }^{4}$ Hal tersebut mungkin disebabkan karena kurangnya upaya untuk memberantas $\mathrm{MH}$, baik dari pihak masyarakat maupun dukungan Pemerintah. Sosialisasi serta penyuluhan kesehatan perlu dilakukan dalam upaya memberantas $\mathrm{MH}$.

Ditinjau dari umur, penderita $\mathrm{MH}$ paling banyak terdapat pada kelompok umur 25-44 tahun yaitu sebanyak 52 pasien (46,4\%) dan tidak ditemukan penderita $\mathrm{MH}$ pada kelompok umur $<4$ 
tahun. Hal ini sesuai dengan penelitian yang dilakukan oleh Seran di Rawat Inap BLU RSUP Prof. Dr. R. D. Kandou Manado tahun 2009-2010, dimana distribusi penderita $\mathrm{MH}$ terbanyak terdapat pada kelompok umur 25-44 tahun dan pada kelompok umur $<4$ tahun tidak ditemukan penderita $\mathrm{MH}^{5}$

Berdasarkan jenis kelamin, laki-laki lebih banyak ditemukan daripada perempuan. Jumlah penderita yang berjenis kelamin laki-laki adalah 72 pasien $(64,3 \%)$ dan yang berjenis kelamin perempuan adalah 40 pasien $(37,5 \%)$. Perbandingan keduanya ialah 1,8 : 1 . Suhariyanto melaporkan bahwa di RSUP Manado pada tahun 1999, penderita lakilaki lebih banyak daripada perempuan, yaitu perbandingannya $1,8: 1{ }^{6}$ Keadaan tersebut kemungkinan disebabkan karena laki-laki cenderung lebih sering beraktivitas diluar rumah, maka sering terpapar dengan penderita yang menjadi sumber infeksi sehingga resiko untuk tertular kusta lebih besar daripada perempuan. $^{7}$

Berdasarkan tempat tinggal, penderita $\mathrm{MH}$ yang tinggal di kota Manado didapatkan sebanyak 57 pasien (50,9\%) dan di luar kota Manado sebanyak 55 pasien (49,1\%). Dari hasil penelitian, penderita $\mathrm{MH}$ yang tinggal di kota Manado paling banyak berasal dari kecamatan Singkil, yaitu berjumlah 14 pasien (12,5\%). Penelitian sebelumnya yang dilakukan oleh Rompas pada tahun 2009-2011 menunjukkan hasil yang sama, dimana kota Manado merupakan tempat tinggal yang paling banyak ditemukan. Hal ini disebabkan karena kepadatan penduduk di kota Manado lebih besar dibandingkan daerah lain dan mengingat juga RSUP Prof. Dr. R. D. Kandou terletak di Manado memungkinkan pasien yang bertempat tinggal di kota Manado lebih memilih Rumah Sakit tersebut untuk berobat karena alasan jarak yang lebih dekat. ${ }^{4}$ Tingginya angka prevalensi $\mathrm{MH}$ di kecamatan Singkil mungkin disebabkan karena tingkat kepadatan penduduk di Singkil yang tinggi, dan sosial ekonomi yang kurang. Namun, perlu dilakukan penelitian yang lebih lanjut untuk mengetahui penyebab pasti dari hal tersebut.

Ditinjau dari tipe $\mathrm{MH}$, tipe Multibasiler lebih banyak ditemukan daripada tipe Pausibasiler. Terdapat sebanyak 100 pasien (89,3\%) yang menderita $\mathrm{MH}$ tipe Multibasiler, sedangkan tipe Pausibasiler berjumlah 12 pasien $(10,7 \%)$. Hal ini sesuai dengan penelitian yang dilakukan oleh Rosvanti A dkk di Divisi Kusta Unit Rawat Jalan (URJ) Kesehatan Kulit dan Kelamin RSU DR. Soetomo Surabaya tahun 2006-2008, ditemukan lebih banyak penderita $\mathrm{MH}$ dengan tipe Multibasiler, yaitu berjumlah 24 penderita $(85,71 \%)$ dan penderita $\mathrm{MH}$ dengan tipe Pausibasiler berjumlah 4 pasien $(14,29 \%) .{ }^{8}$ Berdasarkan data Dinas Kesehatan Provinsi Sulawesi Utara tahun 2012, didapatkan jumlah penderita $\mathrm{MH}$ dengan tipe Multibasiler sebanyak 405 penderita (91,2\%) dan tipe Pausibasiler sebanyak 39 penderita $(8,2 \%){ }^{3}$

Dari klasifikasi reaksi $\mathrm{MH}$, reaksi ENL lebih banyak ditemukan daripada reaksi reversal. Didapatkan sebanyak 18 pasien (16\%) mengalami reaksi ENL dan sebanyak 4 pasien (3,6\%) mengalami reaksi reversal. Namun, terdapat 90 penderita $\mathrm{MH}$ (80,4\%) yang tidak mengalami reaksi ENL maupun reversal. Hal ini sesuai dengan hasil penelitian Seran E di Rawat Inap BLU RSUP Prof Dr. R. D. Kandou tahun 2009-2010, yang menemukan bahwa pasien $\mathrm{MH}$ dengan reaksi ENL lebih banyak ditemukan daripada reaksi reversal dengan jumlah pasien sebanyak 25 pasien (92,59\%) dan 2 pasien $(7,40 \%){ }^{5}$ Reaksi ENL timbul terutama pada tipe lepromatosa polar (LL) dan borderline lepromatosa (BL), sehingga makin tinggi tingkat multibasiler makin besar pula kemungkinan timbulnya ENL. ${ }^{1}$

Berdasarkan tingkat kecacatan, ditemukan sebanyak 18 pasien $(16,1 \%)$ pada tingkat 0,11 pasien (9,8\%) pada tingkat 1 dan 9 pasien $(8,1 \%)$ pada tingkat 2. Adapun sebanyak 38 pasien (33,9\%) 
yang tidak diperiksa tingkat kecacatan. Terdapat pula sebanyak 36 pasien (32,1\%) yang tidak ditemukan datanya, sehingga didapatkan kesulitan saat dievaluasi. Berdasarkan penelitian Putra I dkk di Divisi Kusta, URJ Penyakit Kulit dan Kelamin, RSUD Dr. Soetomo Surabaya tahun 2004-2006 didapatkan jumlah penderita $\mathrm{MH}$ dengan tingkat kecacatan 0 sebanyak 663 pasien (70,2\%), tingkat kecacatan 1 sebanyak 213 pasien (22,5\%), dan tingkat kecacatan 2 sebanyak 69 pasien (7,3\%). ${ }^{7}$ Tingginya angka kecacatan tingkat 1 memerlukan perhatian khusus sebab apabila tidak ditangani dengan tepat, kecacatan tingkat 1 akan berkembang menjadi kecacatan tingkat 2. ${ }^{7}$ Dalam penelitian saat ini, pasien dengan tingkat kecacatan 0 lebih banyak dari tingkat 1 dan tingkat 2, hal itu dapat menunjukkan bahwa adanya kesadaran berobat lebih dini yang tinggi dari penderita $\mathrm{MH}$ sehingga kecacatan dapat dicegah.

Ditinjau dari riwayat berobat sebelumnya, didapatkan 15 pasien $(13,4 \%)$ pernah melakukan MDT sebelum datang ke poliklinik kulit dan kelamin RSUP Prof. Dr. R. D. Kandou Manado dan 61 pasien lainnya (54,5\%) tidak pernah. Terdapat 36 pasien (32,1\%) yang datanya tidak ditemukan. Mengetahui riwayat berobat sebelumnya dari pasien penting untuk kepentingan terapi selanjutnya. Selain itu, agar dapat mencegah terjadinya reaksi dari $\mathrm{MH}$.

\section{SIMPULAN}

Dalam periode Januari-Desember 2012 di poliklinik kulit dan kelamin RSUP Prof. Dr. R. D. Kandou Manado ditemukan jumlah penderita $\mathrm{MH}$ meningkat dari tahun sebelumnya, dengan kelompok umur terbanyak 25-44 tahun, jenis kelamin terbanyak laki-laki, tempat tinggal terbanyak kecamatan Singkil, tipe MH terbanyak tipe Multibasiler, reaksi ENL lebih banyak ditemukan daripada reaksi reversal, tingkat kecacatan 0 lebih banyak dari tingkat 1 dan tingkat 2, dan riwayat pengobatan terbanyak belum pernah melakukan pengobatan MDT sebelumnya.

\section{SARAN}

Perlu dilakukan penyuluhan kesehatan agar resiko penularan $\mathrm{MH}$ dapat berkurang dan kiranya kesadaran untuk berobat semakin tinggi.

\section{DAFTAR PUSTAKA}

1. Kosasih A. Kusta. Dalam: Djuanda A, Hamzah M, Aisah S editor. Ilmu Penyakit Kulit dan Kelamin. Edisi keenam. Jakarta:FKUI;2011.h.73-86.

2. World Health Organization. Leprosy fact sheet. 2012 Sept [diakses 5 Sept 2013]. Available from: http://www.who.int/mediacentre/facts heets/fs101/en/

3. Situasi Kusta di Provinsi Sulawesi Utara. Dinas Kesehatan Provinsi Sulawesi Utara : 2011- 2012.

4. Rompas C. Profil Pasien Morbus Hansen di Poliklinik Kulit dan Kelamin BLU RSUP Prof. DR. R. D. Kandou[skripsi]. Manado:FK UNSRAT;2013.

5. Seran EL. Profil Penderita Morbus Hansen Rawat Inap di RSUP. Prof. DR. R.D. Kandou[skripsi]. Manado:FK UNSRAT;2011.

6. Suhariyanto B. Kusta di RSUD Dr. Soebandi Jember. Berkala Ilmu Kesehatan Kulit dan Kelamin. 2005;17:10-3.

7. Putra I, Fauzi N, Agusni I. Kecacatan pada penderita kusta baru di Divisi Kusta URJ penyakit kulit dan kelamin RSUD Dr. Soetomo Surabaya periode 2004 - 2006. Berkala Ilmu Kesehatan Kulit dan Kelamin. 2009;17:9-17.

8. Rosvanti A, Dewi D, Hadimulyono M, Listiawan L. Penyakit kusta anak baru sebagai tolak ukur derajat endemisitas penyakit kusta. Berkala Ilmu Kesehatan Kulit dan Kelamin. 2010;22:91-6. 